\title{
Barcoding and Phylogenetic Inferences in Nine Mugilid Species (Pisces, Mugiliformes)
}

\author{
Neonila Polyakova1,*, Alisa Boutin ${ }^{2}$, Vladimir Brykov ${ }^{1,3}$ \\ ${ }^{1}$ A.V. Zhirmunsky Institute of Marine Biology, Far Eastern Branch of Russian Academy of Sciences, \\ Vladivostok 690059, Russia \\ ${ }^{2}$ National Institute of Health, National Institute of Diabetes and Digestive and Kidney Diseases, \\ Bethesda, MD 20892, USA \\ ${ }^{3}$ Far East Federal University School of Natural Sciences, Vladivostok 690012, Russia
}

\begin{abstract}
Accurate identification of fish and fish products, from eggs to adults, is important in many areas. Grey mullets of the family Mugilidae are distributed worldwide and inhabit marine, estuarine, and freshwater environments in all tropical and temperate regions. Various Mugilid species are commercially important species in fishery and aquaculture of many countries. For the present study we have chosen two Mugilid genes with different phylogenetic signals: relatively variable mitochondrial cytochrome oxidase subunit I (COI) and conservative nuclear rhodopsin (RHO). We examined their diversity within and among 9 Mugilid species belonging to 4 genera, many of which have been examined from multiple specimens, with the goal of determining whether DNA barcoding can achieve unambiguous species recognition of Mugilid species. The data obtained showed that information based on COI sequences was diagnostic not only for species-level identification but also for recognition of intraspecific units, e.g., allopatric populations of circumtropical Mugil cephalus, or even native and acclimatized specimens of Chelon haematocheila. All RHO sequences appeared strictly species specific. Based on the data obtained, we conclude that COI, as well as RHO sequencing can be used to unambiguously identify fish species. Topologies of phylogeny based on RHO and COI sequences coincided with each other, while together they had a good phylogenetic signal.
\end{abstract}

Keywords: Mugilidae, phylogenetic relationships, barcoding, $\mathrm{COI}, \mathrm{RHO}$

\section{INTRODUCTION}

The unequivocal identification and classification of living organisms to the species level frequently relies on genetic evidence. Specific DNA sequences act as unrepeatable signatures and therefore constitute a unique DNA barcode for each species. Hebert et al. (2003) proposed that a single gene sequence would be sufficient to differentiate all, or at least the vast majority of animal species, and proposed the use of the mitochondrial DNA gene cytochrome oxidase subunit I (COI) as a global bioidentification system for animals. Initiatives, such as The Barcode of Life Database (http: //www. barcodinglife.org) including The Fish Barcode of Life (http: //www.fishbol.org), use a DNA-based identification system based on a relatively small fragment of COI.

However, the approach is not without controversy (Lips- comb et al., 2003; Moritz and Cicero, 2004). For a barcoding approach to species identification to succeed, within-species DNA sequences need to be more similar to one another than to sequences in different species. Recent studies show that this is generally the case, but there are exceptions. Hybridization among species would create taxonomic uncertainty: mitochondrial DNA is maternally inherited and any hybrid or subsequent generation would have the maternal species DNA only. Thus, the idea of a multi-locus DNA barcoding approach is progressively emerging, and limitations of mtDNA underline the requirement of nuclear regions (Frézal and Leblois, 2008). It is clear that longer length DNA barcodes will provide more efficient identification labels. Barcode efficiency can be further improved by the simultaneous use of genes showing different evolutionary rates and genomic positions.

\footnotetext{
(C) This is an Open Access article distributed under the terms of the Creative Commons Attribution Non-Commercial License (http://creativecommons.org/ licenses/by-nc/3.0/) which permits unrestricted non-commercial use, distribution, and reproduction in any medium, provided the original work is properly cited.

*To whom correspondence should be addressed

Tel: 7-423-2310419, Fax: 7-423-2310900

E-mail: nila.polyakova@gmail.com 
RHOopsin, a nuclear gene encoding a transmembrane Gprotein-coupled receptor for visual transduction cascade, proved to be very suitable for barcoding purposes because it has a single copy in the genome, does not contain introns in Teleostei fishes, its evolutionary rate in fish is less than 2-fold lower than, for example, cyt $b$ gene $(0.167$ vs. 0.247$)$, and RHO trees contain a high number of well supported Teleostei clades (Chen et al., 2003).

Here we examine the diversity of two genes with different phylogenetic signal: relatively variable mitochondrial COI and conservative nuclear RHOopsin (RHO) within and among 9 Mugilid species belonging to 4 genera, many of which have been examined from multiple specimens, with the goal of determining whether DNA barcoding can achieve unambiguous species recognition of Mugilid species.

Grey mullets of the family Mugilidae (Pisces, Mugiliformes) are distributed worldwide and inhabit marine, estuarine, and freshwater environments in all tropical and temperate regions. Various Mugilid species are commercially important species in fishery and aquaculture of many countries. Mugilid taxonomy still has not been finalized. The family includes from 14 to 20 genera recognized as valid according to the most recent revisions and 55 currently recognized species (Thomson, 1997; Nelson, 2006). Most of them are representatives of Liza, Chelon, and Mugil genera.

\section{MATERIALS AND METHODS}

\section{Sampling, DNA extraction, polymerase chain reaction (PCR) amplification and sequencing}

One to seven specimens were collected for each of the nine species of Mugilidae (Table 1). DNA extracts were prepared from either muscle or heart tissue or fin clips preserved in 95\% ethanol alcohol according to the protocol of Sambrook et al. (1989). Amplification of the COI gene fragments was carried out using the primers: FishF1 (5'-TCAACCAACCA CAAAGACATTGGCAC-3') and FishR1 (5'-TAGACTTCT GGGTGGCCAAAGAATCA-3') (Ward et al., 1994). Primers RHOO545 (5'-GCAAGCCCATCAGCAACTTCCG-3') and RHOO1039 (5'-TGCTTGTTCATGCAGATGTAGA-3') (Chen et al., 2003) were used to amplify the RHO gene fragments.

PCRs were conducted for both genes with a total volume of $25 \mu \mathrm{L}$ consisting of approximately $50 \mathrm{ng}$ of template DNA, $0.25 \mu \mathrm{M}$ of each primer, $2.5 \mu \mathrm{L}$ of $10 \times$ PCR reaction buffer, $2 \mathrm{mM}$ of each dNTP, and $1 \mathrm{U}$ of Taq DNA polymerase (Sibenzyme, Russia). PCR consisted of an initial denaturation step at $94^{\circ} \mathrm{C}$ for $5 \mathrm{~min}$., followed by 30 cycles of denaturation at $94^{\circ} \mathrm{C}$ for $30 \mathrm{~s}$, annealing for $30 \mathrm{~s}$ at $60^{\circ} \mathrm{C}$ for COI gene fragment and $55^{\circ} \mathrm{C}$ for $\mathrm{RHO}$ gene fragments and extension at $72^{\circ} \mathrm{C}$ for $1 \mathrm{~min}$. The terminal extension was at $72^{\circ} \mathrm{C}$ for 10 min. Aliquots $(3 \mu \mathrm{L})$ of amplicons were examined in $1.5 \%$ gels, stained with ethidium bromide, and photographed upon transillumination. DNA fragments were cut from the agarose gels, frozen-thawed, and re-PCRed under the same conditions. The rePCRed products were precipitated with ethyl alcohol and vacuum dried. Then they were sequenced under conditions recommended by the manufacturer, using the BigDye Terminator v.3.1 Cycle Sequencing Kit (Applied Biosystems, Foster City, CA, USA). Electrophoreses of sequencing products were made in ABI Prism 3130 DNA sequencer in $50 \mathrm{~cm}$ capillary array with polymer POP-7.

\section{Phylogenetic analyses}

The sequences of COI and RHO gene fragments were analyzed both separately and together. DNA sequences were aligned using Clustal W 1.8 in MEGA 5.05. Evolution models and parameters were separately selected for COI and RHO and were then used in the following analyses.

COI sequence divergences were calculated using the Hasegawa, Kishino, and Yano (HKY85+ G) model (Hasegawa et al., 1985) as the appropriate model of sequence evolution chosen on the basis of hierarchical likelihood ratio tests (LRTs) as implemented in ModelTest 3.8 (Posada and Crandall, 1998). RHO sequence divergences were estimated using MEGA 5.05 by Kimura 2-parameter model. Saturation levels of each gene fragment and the combined data set were assessed by plotting transitions and transvertions accumulation for each pair of haplotypes against Hasegawa, Kishino, and Yano distances for COI and Kimura 2 distances for RHO in DAMBE 4.5.2 and MEGA 5.05.

Data were analyzed using three approaches, neighbour joining (NJ), maximum parsimony (MP), and Bayesian inference $(\mathrm{BI})$. NJ, MP and BI trees were created to provide a graphic representation of the patterning of divergence between species computed in MEGA ver. 5.05 and MrBayes 3.2.1. MP analyses were performed using heuristic searches with 50 random stepwise additions and tree bisection-reconnection branch swapping. Bootstrap analyses were used to assess the relative robustness of branches with 1,000 replicates. BI analyses were conducted in MrBayes 3.2.1 with the selected best fit models and parameters. Each BI analysis was run over 4,000,000 generations using four Markov Chain Monte Carlo chains and every 200th tree saved. Four thousand trees were discarded as burn-in. The robustness of trees was tested using posterior probability.

Scomberomorus cavalla (Liu, 2010) and Tribolodon hakonensis were included in all analyses as outgroups. The sequences of Scomberomorus cavalla were taken from GenBank (Table 1).

All sequences are available in Genbank under the accession 
Table 1. List of Mugilidae species studied with collection locality, number of individuals sequenced, GenBank accession number

\begin{tabular}{|c|c|c|c|c|}
\hline \multirow{2}{*}{$\begin{array}{c}\text { Species, } \\
\text { common name }\end{array}$} & \multirow{2}{*}{ Collection locality } & \multirow{2}{*}{$\begin{array}{l}\text { Individual } \\
\text { sequenced }\end{array}$} & \multicolumn{2}{|c|}{ GenBank accession No. } \\
\hline & & & $\mathrm{CO} 1$ & rhod \\
\hline $\begin{array}{l}\text { Chelon labrosus, } \\
\text { thicklip mullet }\end{array}$ & Tyrrhenian Sea, Orbetello Lagoon, Italy & 2 & EU392233 & JX298796 \\
\hline $\begin{array}{l}\text { Liza aurata, } \\
\text { golden grey mullet }\end{array}$ & $\begin{array}{l}\text { Azov Sea, Tuzla, Cape, Russia } \\
\text { Tyrrhenian Sea, Orbetello Lagoon, Italy }\end{array}$ & $\begin{array}{l}2 \\
2\end{array}$ & $\begin{array}{l}\text { EU392234 } \\
\text { EU392235 }\end{array}$ & $\begin{array}{l}J X 298792 \\
J X 298791\end{array}$ \\
\hline $\begin{array}{l}\text { Liza haematocheila, } \\
\text { redlip mullet }\end{array}$ & $\begin{array}{l}\text { Azov Sea, Tuzla Cape, Russia } \\
\text { East Sea, South Primorye, Vostok Bay, Russia } \\
\text { Bioresearch Center, Academia Sinica, } \\
\text { ID ASIZP0802104, Taiwan }\end{array}$ & $\begin{array}{l}2 \\
2 \\
1\end{array}$ & $\begin{array}{l}\text { EU392236 } \\
\text { EU392237 } \\
\text { EU392238 }\end{array}$ & $\begin{array}{l}\text { JX298799 } \\
\text { JX298800 } \\
\text { JX298801 }\end{array}$ \\
\hline $\begin{array}{l}\text { Chelon macrolepis, } \\
\text { largescale mullet }\end{array}$ & $\begin{array}{l}\text { Bioresearch Center, Academia Sinica, } \\
\text { ID ASIZP0800182, Taiwan }\end{array}$ & 2 & EU392239 & JX298798 \\
\hline $\begin{array}{l}\text { Liza ramado, } \\
\text { thinlip mullet }\end{array}$ & Tyrrhenian Sea, Orbetello Lagoon, Italy & 2 & EU392240 & JX298797 \\
\hline $\begin{array}{l}\text { Liza saliens, } \\
\text { leaping mullet }\end{array}$ & Tyrrhenian Sea, Orbetello Lagoon, Italy & 1 & EU392241 & JX298795 \\
\hline $\begin{array}{l}\text { Chelon subviridis, } \\
\text { greenback mullet }\end{array}$ & $\begin{array}{l}\text { Bioresearch Center, Academia Sinica, } \\
\text { ID ASIZP0800195, Taiwan }\end{array}$ & 1 & EU392242 & JX298794 \\
\hline $\begin{array}{l}\text { Mugil cephalus, } \\
\text { flathead mullet }\end{array}$ & $\begin{array}{l}\text { Azov Sea, Tuzla Cape, Russia } \\
\text { East Sea, South Primorye, Vostok Bay Russia } \\
\text { Mediterranean Sea, Sardinia, } \\
\text { San Giovanni Lagoon, Italy }\end{array}$ & $\begin{array}{l}2 \\
2 \\
2\end{array}$ & $\begin{array}{l}\text { EU392243 } \\
\text { EU392244 } \\
\text { EU392245 }\end{array}$ & $\begin{array}{l}\text { JX298802 } \\
\text { JX298803 } \\
\text { JX298804 }\end{array}$ \\
\hline & $\begin{array}{l}\text { Bioresearch Center, Academia Sinica, } \\
\text { ID ASIZP0800468, Taiwan }\end{array}$ & 1 & EU392246 & JX298805 \\
\hline $\begin{array}{l}\text { Moolgarda cunnesius, } \\
\text { longarm mullet }\end{array}$ & $\begin{array}{l}\text { Bioresearch Center, Academia Sinica, } \\
\text { ID ASIZP0800182, Taiwan }\end{array}$ & 1 & EU392247 & JX298793 \\
\hline
\end{tabular}

numbers shown in the Table 1.

\section{RESULTS}

\section{Sequence characteristics}

A total of 9 Mugilid species were analyzed, generating (because of multiple specimens for most species) a total of 60 sequences. Approximately $652 \mathrm{bp}$ were amplified and sequenced from the $5^{\prime}$ region of the COI gene from mitochondrial DNA. No insertions, deletions or stop codons were observed in any sequence. One hundred ninty-eight variable sites were revealed, most of them $(88.9 \%)$ were attributable to the the 3rd codon base, $10.1 \%$ to the 2 nd, and $1 \%$ to the 1 st codon base. Fourteen nucleotide substitutions resulted in amino acid replacement.

The GC content of the Liza-Chelon-Moolgarda species was higher of $M$. cephalus ( $48.1 \%$ vs. $45.0 \%$ ) due to a higher GC content of the first ( $58 \%$ vs. $55 \%$ ) and, especially, second (54\% vs. $43 \%)$ and third (44\% vs. $32 \%$ ) codon base in the former.
The HKY85 distance of individuals within L. haematocheila was $0.17 \%$ compared to $3.22 \%$ within M. cephalus specimens. Mean divergence among congeneric species was $12.54 \%$. Mean divergence among species within the family increases to $21.8 \%$ Mugil vs. Liza, and Mugil vs. Chelon, $20.5 \%$ Mugil vs. Moolgarda, 18.2\% Moolgarda vs. Liza, and Moolgarda vs. Chelon, and only $10.6 \%$ Liza vs. Chelon.

RHOopsin sequences were 515 bp length. All RHOopsin sequences were species-specific. We observed no intraspecific variability, except one nucleotide substitution in 3rd codon position in L. aurata individuals from Azov and Mediterranean Seas that did not result in amino acid replacement.

Forty-four variable sites were revealed, 28 of them were found to be parsimony-informative, most of them $(67 \%)$ were attributable to the $3 \mathrm{rd}$ codon base, $5 \%$ to the $2 \mathrm{nd}$, and $28 \%$ to the 1st codon base. Eight nucleotide substitutions resulted in amino acid replacement. GC content was about the same in all the species studied-53-55\%. The level of divergence due to conservativeness of RHO gene was much lower compared to COI ranging from only $0.4 \%$ between $L$. saliens and C. labrosus and $5 \%$ between L. aurata and M. cephalus. 


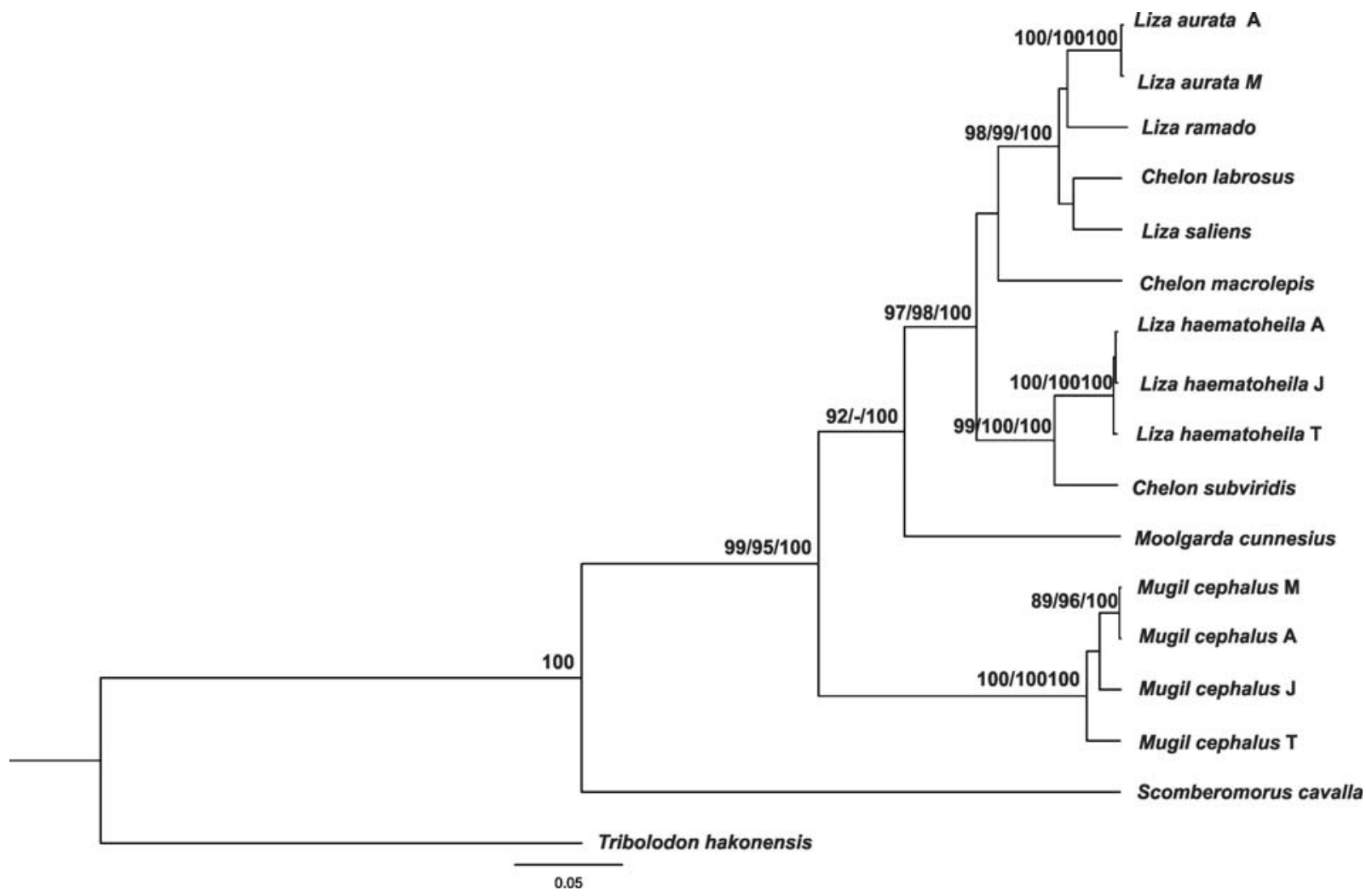

Fig. 1. Bayesian inference (BI) tree based on combined cytochrome oxidase subunit I and RHO gene fragments. Numbers above the branches represent the bootstrap values $>75$ for neighbour joining and maximum parsimony trees as well as posterior probabilities values for BI-tree with virtually the same topology. A, Azov Sea; M, Mediterranean Sea; J, East Sea; T, Taiwan.

\section{The phylogenetic relationships of Mugilidae}

Although DNA barcoding aims to develop species identification systems, some phylogenetic signal was apparent in the data. No saturation was detected for each dataset of $\mathrm{COI}$ and RHO sequences. The plots of transversion and transitions against genetic distances were almost linear. Therefore, all substitutions in COI and RHO gene fragments were used for phylogenetic reconstructions.

In all cases, no significant differences among the NJ, MP, and $\mathrm{BI}$ tree topologies based on COI and RHO gene sequences were found. The consensus tree obtained from Bayesian analysis of COI dataset was completely identical in topology to the one produced using NJ and MP analysis. The topologies of NJ, MP, and BI trees based on RHO gene analyses were very similar to each other. Thus only the Bayesian tree based on combined COI and RHO gene fragments was presented together with major nodal support values for NJ and MP(Fig. 1).

Haplotypes of the same species were always clustered together in both phylogenetic reconstructions based on COI, RHO and combined COI and RHO gene fragments dataset. All haplotypes of M. cephalus sampled from the seas of Azov,
Mediterranean and Japan and near the water of Taiwan formed the monophyletic cluster on the phylogenetic tree based on COI dataset as well as RHO sequences with high bootstrap and posterior probabilities values (BP, PP). The haplotypes of $M$. cephalus appeared basal as sister group to all other Mugilidae on both phylogenetic trees (Fig. 1). L. haematocheila haplotypes sampled in the East Sea and Okhotsk and near Taiwan were clustered together with high nodal support. The closest relative of L. haematocheila was C. subviridis (Fig. 1). Chelon macrolepis was intermediate between Mediterranean mullets and L. haematocheila-C. subviridis cluster. Chelon labrosus grouped with L. aurata, L. ramada, L. saliens to form a monophyletic clade (Fig. 1), which turned out to exclusively comprise species distributed in MediterraneanAzov waters. Liza aurata haplotypes sampled in Mediterranean and Azov seas clustered together (Fig. 1). The other Chelon species $C$. subviridis together with $L$. haematochalia sampled, all from the Pacific as well as the specimens acclimatized on Azov Sea from the East Sea, formed a distinct clade.

Although the phylogenetic trees based on COI and RHO sequences were significantly similar to each other, there were 
differences between them. Haplotypes of M. cephalus sampled in Azov-Mediterranean, the East Sea and Taiwan resolved into three clusters on the phylogenetic tree based on COI sequences with high BP and PP support. Haplotypes of $L$. haematocheila consisted of three lineages, one of which was acclimatized individuals sampled in Azov Sea, and two were from the East Sea and near Taiwan. No variation on RHO sequences was revealed within species $M$. cephalus and $L$. haematoheila. Topology of C. macrolepis and M. cunnesius branches was unstable in the phylogenetic tree based on RHO sequences, BP and PP support were low.

\section{DISCUSSION}

Molecular markers are used for explanation and refining the taxonomic and phylogenetic relationships in the groups of the species. Furthermore, molecular markers are used for the accurate and unambiguous identification of fish and fish product from eggs to adult, and it is important in many areas.

Although phylogenetic analyses of Mugilidae species were carried out based on $16 \mathrm{~S}$ and $12 \mathrm{~S}$ rRNA mtDNA sequences (Liu et al., 2010), Phe 12SrRNA, cyt b and COI (Heras et al., 2009), three mtDNA loci 16SrRNA, COI and cyt b (Durand et al., 2012), the author supposed that employing slowerevolved and independent nuclear genes might prove helpful to provide molecular systematic of Mugilidae.

For the barcoding we proposed to use not only variable mitochondrial cytochrome oxidase subunit I, but also the highly conserved nuclear RHOopsin gene, which has not previously been used for such purposes. The use of the nuclear genes for the barcoding is especially important in the case of hybridization among species. The mitochondrial COI gene is the most efficient gene marker. However, in some cases 5 '-COI "barcoding" region is not enough and even be misleading for purposes of identification due interspecific COI recombination reflecting putative historical hybridization events between species (Balakirev et al., 2012).

All 9 species can be differentiated by both COI and RHO. The lack of stop codons is consistent with all amplified sequences being functional mitochondrial COI sequences, and that, together with the fact that all amplified sequences were about 628-652 bp in length, suggests that NUMTs (nuclear DNA sequences originating from mitochondrial DNA sequences) were not sequenced (vertebrate NUMTS are typically smaller than $600 \mathrm{bp}$ (Zhang and Hewitt, 1996).

The data obtained showed that information based on COI sequences was diagnostic not only for species level identification but also for recognition of intraspecific units, e.g., allopatric populations of circumtropical M. cephalus, whose pronounced population genetic structure is well-known, or even native and acclimatized specimens of L. haematocheila.

COI sequences of each specimen of each sample proved to be identical. We found no difference within each of $M$. cephalus and L. aurata samples from Azov and Mediterranean Seas. Sequences of geographically remote L. haematocheila (Azov Sea, East Sea, and Taiwan) and M. cephalus (Azov-Mediterranean, East Sea, and Taiwan) had their own haplotypes, 1-2 nucleotide substitutions being observed between the redlip mullet specimens causing 1 amino acid substitution, while 17-31 nucleotide substitutions being revealed between the flathead mullet specimens, which resulted in 4 amino acid substitutions. COI short DNA sequence provides sufficient identification labels in terms of nucleotide positions to discriminate even between congeneric fish species (Hebert et al., 2003) despite the intraspecific variation that was especially pronounced between geographically distant $M$. cephalus specimens.

All RHOopsin sequences were species-specific. Even $M$. cephalus specimens that were geographically remote and deeply diverged by mtDNA appeared to be identical. Thus, RHO sequences can be considered useful for barcoding purposes owing to low or zero intraspecific variation and the absence of problems connected with introgressive hybridization as may emerge in the case of mtDNA.

The clades revealed after bootstrapping generally corresponded well with expectations. Topologies of NJ, MP and BI trees conformed to our previous data (Semina et al., 2007) based on PCR-restiction fragment length polymorphismanalysis of extended mtDNA segments.

The data obtained indicated that $M$. cephalus was the most genetically distant from the rest of the species, which conformed to the results of other authors based on mitochondrial DNA, allozyme, gemoglobin, and karyologic study (Cataudella et al., 1974; Rizotti, 1993; Caldara et al., 1996; Rossi et al., 1998, 2004; Gornung et al., 2001, 2007; Papasotiropoulos et al., 2001, 2002, 2007; Turan et al., 2005; Imsiridou et al., 2007). Three mitochondrial lineages of $M$. cephalus based on COI sequences had the regional distribution (Fig. 1). One corresponded the Mediterranean lineage included M. cephalus from Morocco, Tunisia and France and two conformed to the lineages revealed in the Pacific region (Durand et al., 2012). We found that all Mediterranean-Azov Chelon and Liza species clustered together as well as all Pacific Chelon and Liza. The results conformed the close genetic relation of Chelon and Liza representatives. Many other researchers also stated the close relationships of these genera. Morphologic (pharyngobranchial organ), cytogenetic, genetic (mitochondrial DNA), allozyme analyses performed by other authors, revealed no substantial difference between Mediterranean Liza species and C. labrosus (Cataudella et al., 1974; Caldara et al., 1996; Gornung et al., 2001, 2007; 
Murgia et al., 2002, Papasotiropoulos et al., 2002, 2007; Rossi et al., 2004; Turan et al., 2005; Imsiridou et al., 2007; Durand et al., 2012). We consider that molecular phylogeny offered no evidence for distinguishing Liza from Chelon, leading us to challenge their validity. Therefore, taking into account the scientific issue data, our results point out the necessity for taxonomic revision of Chelon and Liza genera.

Based on the data obtained, we conclude that COI, as well as RHO sequencing, can be used to unambiguously identify fish species. Topologies of phylogeny based on COI and RHO sequences coincided with each other, while together they had a good phylogenetic signal.

\section{ACKNOWLEDGMENTS}

We would like to heartily thank Kwang-Tsao Shao, Anna Rita Rossi, Mikhail Makhotkin, Vladimir Omelchenko, Vasiliy Radashevsky, Alexandr Sokolovsky for their kind help providing samples, thus making this study possible. The work described in this paper is supported by FEB RAS grant No. 12-I-P30-08.

\section{REFERENCES}

Balakirev ES, Krupnova TN, Ayala FJ, 2012. DNA variation in the phenotypically-diverse brown alga. Saccharina japonica. BMC Plant Biology, 12:108.

Caldara F, Bargelloni L, Ostellari L, Penzo E, Colombo L, Patarnello T, 1996. Molecular phylogeny of grey mullets based on mitochondrial DNA sequence analysis: evidence of differential rate of evolution at the intrafamily level. Molecular Phylogenetics and Evolution, 6:416-424.

Cataudella S, Civitelli MV, Capanna E, 1974. Chromosome complements of the Mediterranean mullets (Pisces, Perciformes). Caryologia, 27:93-105.

Chen WJ, Bonillo C, Lecointre G, 2003. Repeatability of clades as a criterion of reliability: a case study for molecular phylogeny of Acanthomorpha (Teleostei) with larger number of taxa. Molecular Phylogenetics and Evolution, 26:262-288.

Durand JD, Shen KN, Chen WJ, Jamandre BW, Blel H, Diop K, Nirchio M, Garcia de León FJ, Whitfield AK, Chang CW, Borsa P, 2012. Systematics of the grey mullets (Teleostei: Mugiliformes: Mugilidae): molecular phylogenetic evidence challenges two centuries of morphology-based taxonomy. Molecular Phylogenetics and Evolution, 64:73-92.

Frézal L, Leblois R, 2008. Four years of DNA barcoding: current advances and prospects. Infection, Genetics and Evolution, 8:727-736

Gornung E, Colangelo P, Annesi F, 2007. 5S Ribosomal RNA genes in six species of Mediterranean Grey Mullets: genomic organization and phylogenetic inference. Genome, 50:
787-795.

Gornung E, Cordisco CA, Rossi AR, Innocentiis DS, Crosetti D, Sola L, 2001. Chromosomal evolution in Mugilidae: karyotype characterization of Liza saliens and comparative localization of major and minor ribosomal genes in the six Mediterranean mullets. Marine Biology, 139:55-60.

Hasegawa M, Kishino H, Yano T, 1985. Dating the human-ape split by a molecular clock of mitochondrial DNA. Journal of Molecular Evolution, 22:160-174.

Hebert PDN, Cywinska A, Ball SL, De Waard JR, 2003. Biological identifications through DNA barcodes. Proceedings of the Royal Society B: Biological Sciences, 270:313-321.

Heras S, Roldán MI, Castro MG, 2009. Molecular phylogeny of Mugilidae fishes revised. Reviews in Fish Biology and Fisheries, 19:217-231.

Imsiridou A, Minos G, Katsares V, Karaiskou N, Tsiora A, 2007. Genetic identification and phylogenetic inferences in different Mugilidae species using 5S rDNA markers. Aquaculture Research, 38:1370-1379.

Lipscomb D, Platnick N, Wheeler Q, 2003. The intellectual content of taxonomy: a comment on DNA taxonomy. Trends in Ecology and Evolution, 18:65-66.

Liu JY, Brown CL, Yang TB, 2010. Phylogenetic relationships of mullets (Mugilidae) in China seas based on partial sequences of two mitochondrial genes. Biochemical Systematics and Ecology, 38:647-655.

Moritz C, Cicero C, 2004. DNA barcoding: promise and pitfalls. PLoS Biology, 2:e354.

Murgia R, Tola G, Archer SN, Vallerga S, Hirano J, 2002. Genetic identification of grey mullet species (Mugilidae) by analysis of mitochondrial DNA sequence: application to identify the origin of processed ovary products (Bottarga). Marine Biotechnology, 4:119-126.

Nelson JS, 2006. Fishes of the world. John Wiley \& Sons, Inc., New York, pp. 1-601.

Papasotiropoulos V, Klossa-Kilia E, Alahiotis S, Kilias G, 2007. Molecular phylogeny of grey mullets (Teleostei: Mugilidae) in Greece: evidence from sequence analysis of mtDNA segments. Biochemical Genetics, 45:623-636.

Papasotiropoulos V, Klossa-Kilia E, Kilias G, Alahiotis S, 2001. Genetic divergence and phylogenetic relationships in grey mullets (Teleostei: Mugilidae) using allozyme data. Biochemical Genetics, 39:155-168.

Papasotiropoulos V, Klossa-Kilia E, Kilias G, Alahiotis S, 2002. Genetic divergence and phylogenetic relationships in grey mullets (Teleostei: Mugilidae) based on PCR-RFLP analysis of mtDNA segments. Biochemical Genetics, 40:71-86.

Posada D, Crandall KA, 1998. Modeltest: testing the model of DNA substitution. Bioinformatics, 14:817-818.

Rizotti M, 1993. Fish hemoglobins: the family Mugilidae (Perciformes). Trends in Comparative Biochemistry and Physiology, 1:385-392.

Rossi AR, Capula M, Crosetti D, Sola L, Campton DE, 1998. Allozyme variation in global populations of striped mullet, Mugil cephalus (Pisces: Mugilidae). Marine Biology, 131: 
203-212.

Rossi AR, Ungaro A, De Innosentis S, Crosetti D, Sola L, 2004. Phylogenetic analysis of Mediterranean mugilids by allozymes and 16S mt-rRNA genes investigation: are the Mediterranean species of Liza monophyletic? Biochemical Genetics, 42:301-315.

Sambrook J, Fritsch EF, Maniatis T, 1989. Molecular cloning: a laboratory manual. Cold Spring Harbor Laboratory Press, Cold Spring Harbor, pp. 1-1626.

Semina AV, Polyakova NE, Brykov VlA, 2007. Analysis of mitochondrial DNA: taxonomic and phylogenetic relationships in two fish taxa (Pisces: Mugilidae and Cyprinidae). Biochemistry (Moscow), 72:1349-1355.

Thomson JM, 1997. The Mugilidae of the world. Memoirs of the Queensland Museum, 41:457-562.

Turan C, Caliskan M, Kucuktas H, 2005. Phylogenetic relationships of nine mullet species (Mugilidae) in the Meditteranean Sea. Hydrobiologia, 532:45-51.

Ward RD, Woodwark M, Skibinski DOF, 1994. A comparison of genetic diversity levels in marine, freshwater, and anadromous fishes. Journal of Fish Biology, 44:213-232.

Zhang DX, Hewitt GM, 1996. Nuclear integrations: challenges for mitochondrial DNA markers. Trends in Ecology and Evolution, 11:247-251. 